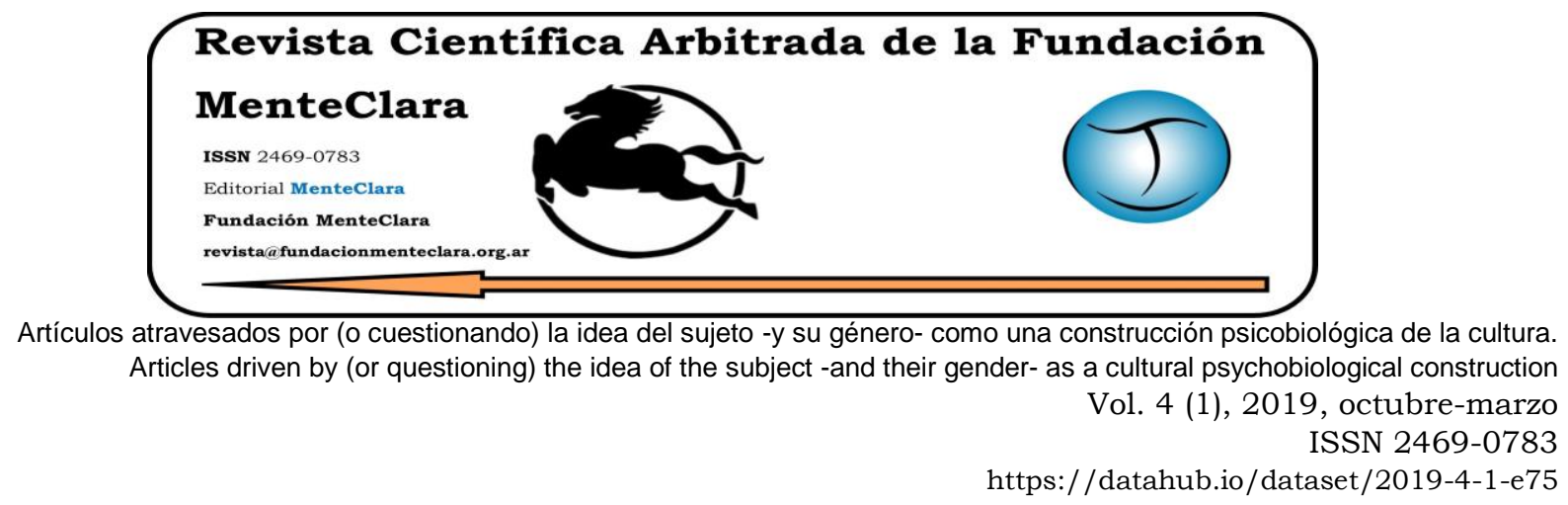

\title{
Editorial Volume 4 (1) 2019 - Development and evolution of the journal
}

DOI: https://doi.org/10.32351/rca.v4.1.75

\section{By Oscar R. Gómez}

\section{Versión en español}

\section{Abstract:}

This editorial describes our journal's evolution since 2016 as well as the actions taken by the editorial committee to achieve objectives that have allowed us to be among the leading journals in the world. It also presents our goal for 2020: To keep on funding authors by covering the processing, editing, and layout charges and to allocate more financial resources to fund authors' research devoted to make visible problems and solutions related to suffering caused by social inequalities.

\section{Development}

We are now three years old and we initiate the fourth one with awards that make us proud. Since our jounal's creation, in January 2016, we have had the support of the CAICYT-CONICET staff and those responsible for REDIB. This support was probably given because our editorial committee managed to bring together a team of highly seasoned researchers in scientific research methodology -especially Gastón Becerra- and in the development of the PHP code of the Open Journal System (OJS) platform.

The specificity of our articles quickly generated significant traffic -according to Alexa measurements- to the extent that less than a year after being launched online, JournalTocs added our journal to its catalog with no request from our part.

JournalTocs, the catalog of the Heriot-Watt University of Edinburgh, United Kingdom, states on its website: "JournalTOCs takes special care to include only the best-qualified journals in their fields, guaranteeing quality results". Some of their selection criteria are the following: 
"Mandatory requirements: 2-The magazine has published at least four issues or volumes in the last two previous years.

Additional requirements: 7-The articles published in the journal have DOI identifiers. 8-The journal is registered with relevant organizations for example, CrossRef, COPE, LOCKSS)"

In November 2016, by means of a piece of news (MacLeod, 2016), we learned that we had been included in JournalTocs, even without meeting points 2,7 or 8 and that at that time we were part of an elite of 2746 publishers worldwide with only 9 months of existence.

This prompted us to break our declared biannual frequency and publish a third issue in December 2016. This is when we appreciate the work of REDIB -the IberoAmerican Network of Innovation and Scientific Knowledge-, where we had been already indexed, which pointed out our "incorrectness" for publishing a third issue. With their help and experience, they showed the way to correct it by calling it an "extraordinary issue".

Such a support and assistance were not limited only to editorial methodological matters: in a joint effort between our team of programmers and theirs, they showed us the way to become one of the few journals that, through the OAI-PMH 2.0 protocol, offer, in addition to basic metadata, the complete list of cited references so that libraries index our articles as in the following example.

Due to this support, we resolved to be up to our evaluators, quadrupling the financial resources to fund the publication of articles, implementing the services of DOI, joining as members of CrossRef, COPE, and Lockss -points 7 and 8 of JournalTocs- and committing ourselves to strictly comply, before REDIB, with the journal's declared biannual frequency.

Such editorial decision led ERIH Plus -the European Reference Index for the Humanities and Social Sciences- to include us in its catalog in December 2018. ERIH is the largest international evaluator in terms of high quality and high impact research data.

Upon meeting all the requirements for peer-reviewed scientific publications for three years, we requested to be audited by the international evaluating entities that require journals to be at least three years old in order to apply. Accordingly, and with 
the invaluable collaboration of CAICYT-CONICET, Latindex -especially Ana Maria Flores, Carlos Authier, and Alicia Aparicio-, REDALYC, and AmeliCA -Fernando Rodriguez and Eliana Guzmán-, and the DOAJ support staff, -especially Ilaria Favawe started this fourth year achieving the following milestones:

We were given a top-level journal classification in CONICET, green status in Malena and SHERPA/RoMEO, a 100\% check mark for the Latindex catalog evaluation criteria, and the DOAJ quality seal. There are only two Spanish-language Argentinean journals meeting the 38 requirements -which are both essential and desirable- to be listed in the Latindex Catalog: our journal and the Universidad Nacional del Litoral Journal [Revista de Extensión Universitaria de la Universidad Nacional del Litoral]. There are also two Argentinean publications in Spanish awarded with the DOAJ Seal: our journal and Salud Colectiva, of the Universidad de Lanús.

In addition, we are the only journal in Argentina meeting all the requirements the European Research Council will ask academic journals in 2020, as stated in the initiative called Plan S. One of the requirements is that journals should offer articles in formats other than PDF; at present we are offering articles in both HTML and XML, which allows non-Spanish and non-English readers to have an approach to our published articles by using the HTML format in combination with Google Translator. This resulted in receiving a lot of online traffic from Eastern and Middle East countries, for example, from the library of Ajman University in the United Arab Emirates, where we are currently indexed.

Last but not least, we let you know we will soon change the biannual publication frequency to a continuous one. As our colleagues of Salud Colectiva say: approved, edited, published.

We also put in our 2020 horizon to keep on funding authors the editorial processing fees and editing and layout costs, as well as to fund independent researchers devoted to shed light on problems and solutions related to social inequalities ${ }^{1}$.

\footnotetext{
1 It is written in the Kulanava Tantra: "A brāhmaṇa acquires competence in a year; a kșatriya in two; $a$ vaisya in three, and $a$ śūdra in four. Once withinn the clan, if a südra is first initiated and then a brāhmaṇa is, then such brāhmaṇa owes obedience to the sūudra". Most probably, these ideas inspired Dr. Ambedkar and Savitribai Phule to foster equality among men through education.
} 


\section{Presentation Vol. 4 (1) 2019}

This first 2019 issue, just like the previous ones, follows our publishing guiding principle: "Articles crossed by (or questioning) the idea of the subject-and their genderas a psychobiological construction of culture».

In the Articles section, you will find Mario Guadalupe López Ayala and Israel Osuna Flores research work "Analysis of cyberjournalism in Mexico with an emphasis on the state of Sinaloa", which shows that the best quality cybermedia is concentrated in the country's large cities and that most of the remaining sites are fairly rudimentary services. This, which is due to the fact that there are still many areas and large sectors of the population where Internet services are quite vague, shows that efforts to make people conditions equal should focus on providing Internet services to the most unprotected sectors.

Such a powerful tool used to empower the most depressed sectors, and which was evidenced in the work of Shraddha Kumbhojkar (2018) to show us how Dalits use Internet access to expose and solve their needs, is followed up in this issue by the same author in her research "Access Denied?: Cultural capital and digital access". Her work shows in a quantitative study carried out by the Savitribai Phule Pune University that the sociocultural capital in the form of caste, gender, language and location, has a negative impact on digital access, even if it is free.

This article, in my opinion, leaves an unwritten question open: Is it the political system impeding access to certain levels of information or is it that previous personal web searches of students belonging to the most depressed sectors, which are based on their particular needs or possibilities, determine the eventual poor web search results when researching for academic purposes? This question of key importance could, if the answer is the second option, be answered by recommending to such students to do academic web research by using devices with no previous search and browsing history at all.

Lastly, we include research by Jesús Maria Dapena Botero "Correlate between postpartum depression and lupus erythematosus, from a psychosomatic and psychoanalytical point of view", in which he proposes a line of treatment from the idea of "psychesome" as a unity, overcoming the Cartesian dualism of soul and body, which pairs the notion of a non-dual subject thought in the 7 th century AD by Tantrism, and which, according to the author, is present in Donald Winnicott. 
In the TANTRIC ACT section, we include three articles by Rudolph Bauer "Merleau Ponty: subjectivity as the field of being within beings. Consciousness as existence", "Forms of vitality within embodied consciousness: A phenomenology of invocation" and "Phenomenology of sublime vibration as word and language"

This author, in a sequence of reviews on the works of Husserl, Heidegger, MerleauPonty and texts of Vajrayana Buddhism (tantric), shows us the role of language in the construction of the subject and the notion of no-essence in the being by associating Tantric philosophy with the later development -within the Circle of Eranos- of the protean form of Tantrism called existentialism. This notion of a subject, with a deityfree existence and with no essence able to rise and develop consciousness to endless potentials, is presented by this author as a concrete way to achieve greater human dignity.

... with all the attachments of maya (illusion) cut off, reaching the supreme end of knowledge, with no seed (essence) or impressions ${ }^{2}$ of previous lives, one becomes god. Shiva, L. (VII d.C). Kulanava Tantra.

\footnotetext{
${ }^{2}$ David Hume calls impressions to the basic psychic contents whose changes create the rest of perceptions arising in the mind. They are the sensations, passions and emotions that affect our mind fiercely and vivaciously.
} 


\section{References}

Ambedkar, B. R. (1997). The Buddha and His Dhamma. Gautam Book Center. http://www.columbia.edu/itc/mealac/pritchett/00ambedkar/ambedkar_buddha/

Bauer, R. (2019). Phenomenology of The Sublime Vibration as Word and Language. Revista Cientifica Arbitrada de la Fundación MenteClara, 4(1), 125-139. doi:https://doi.org/10.32351/rca.v4.1.63

Bauer, R. (2019). Forms of Vitality within Embodied Awareness: A Phenomenology of Invocation. Revista Científica Arbitrada de la Fundación MenteClara, 4(1), 95-123. doi:https://doi.org/10.32351/rca.v4.1.62

Bauer, R. (2019). Merleau Ponty: Subjectivity as The Field of Being within Beings. Awareness As Existingness. Revista Científica Arbitrada de la Fundación MenteClara, 4(1), 81-93. doi:https://doi.org/10.32351/rca.v4.1.61

Dapena Botero, J. (2019). Correlate between postpartum depression and lupus erythematosus, from a psychosomatic and psychoanalytical point of view. Revista Científica Arbitrada de la Fundación MenteClara, 4(1), 33-63. doi:https://doi.org/10.32351/rca.v4.1.64

Kumbhojkar, S., Magar, R., \& Ozarkar, S. (2019). Access Denied? : Cultural Capital and Digital Access. Revista Científica Arbitrada de la Fundación MenteClara, 4(1), 65-78. doi:https://doi.org/10.32351/rca.v4.1.70

López Ayala, M., \& Osuna Flores, I. (2019). Analysis of cyberjournalism in Mexico, with an emphasis on the state of Sinaloa. Revista Científica Arbitrada de la Fundación MenteClara, 4(1), 7-30. doi:https://doi.org/10.32351/rca.v4.1.58

MacLeod, R. (2016). 71 More Open Access and subscription Journals added to JournalTOCs. Roddy Macleood`s blog. https://roddymacleod.wordpress.com/category/web 